12,05

\title{
Структура и физические свойства железных нанотрубок, полученных методом темплатного синтеза
}

\author{
(C) Е.Е. Шумская ${ }^{1}$, Е.Ю. Канюков ${ }^{1}$, А.Л. Козловский ${ }^{2,3}$, М.В. Здоровец ${ }^{2,4,5}$, В.С. Русаков ${ }^{6}$, К.К. Кадыржанов $^{3}$ \\ ${ }^{1}$ НПЦ НАН Беларуси по материаловедению, \\ Минск, Беларусь \\ ${ }^{2}$ Институт ядерной физики Республики Казахстан, \\ Алматы, Казахстан \\ ${ }^{3}$ Евразийский национальный университет им. Л.Н. Гумилева, \\ Астана, Казахстан \\ ${ }^{4}$ Уральский федеральный университет им. Б.Н. Ельцина, \\ Екатеринбург, Россия \\ ${ }^{5}$ Национальный исследовательский ядерный университет „МИФИ“, \\ Москва, Россия \\ ${ }^{6}$ Московский государственный университет им. М.В. Ломоносова, \\ Москва, Россия \\ E-mail: lunka7@mail.ru
}

(Поступила в Редакцию 14 сентября 2016 г.)

На базе полиэтилентерефталатовых темплатов методом электрохимического осаждения синтезированы железные нанотрубки с аспектным соотношением порядка 100. Методами сканирующей электронной микроскопии, энергодисперсионного анализа, просвечивающей электронной микроскопии, дифракции электронов, рентгеноструктурного анализа и газопроницаемости проведено детальное исследование структурных и морфологических особенностей нанотрубок. При помощи вибрационной магнитометрии и мессбауэровской спектроскопии определены основные магнитные параметры, а также их зависимость от температуры.

DOI: 10.21883/FTT.2017.04.44281.350

\section{1. Введение}

Магнитные наноструктуры, построенные на основе металлов триады железа (Fe, $\mathrm{Co}, \mathrm{Ni})$, представляют большой интерес как с точки зрения установления фундаментальных основ магнитных взаимодействий, так и с позиции потенциальных приложений. Они перспективны для использования в катализе [1], при доставке лекарств [2] и генов [3], изучении микрореологических процессов [4], а также в качестве контрастных жидкостей [5]. Несмотря на то что свойства металлов триады железа в массивных телах хорошо изучены, структурные и магнитные характеристики в наноразмерных объектах, таких как наночастицы, нанопроволоки и нанотрубки, требуют дополнительного исследования.

Простым методом получения наноматериалов с заданной формой и размерами является шаблонный синтез [6-8]. Он наиболее технологичный, так как позволяет контролировать морфологию, структуру, состав и соответственно магнитные свойства наноструктур за счет изменения ряда внешних параметров: температуры, состава и кислотности электролита, напряжения на электродах и времени осаждения [6,9-11]. В настоящее время довольно хорошо отработаны механизмы получения магнитных нанопроволок с использованием подложек из $\mathrm{Si}[12], \mathrm{Al}_{2} \mathrm{O}_{3}$ [13] и $\mathrm{SiO}_{2}$ [14]. Однако получение нанотрубок на таких подложках ограничено особенностью методики синтеза $[15,16]$. В силу специфической структуры и уникальных свойств более привлекатель- ными для практического применения являются полые наноструктуры, которые за счет меньшей объемной плотности и большей площади поверхности перспективны для использования в качестве элементов наноэлектронных устройств [17], катализаторов [1], носителей при адресной доставке лекарственных средств [18] и химических реакторов [19].

В настоящей работе предлагается простая методика создания железных нанотрубок посредством темплатного синтеза с использованием ионно-трековых полимерных мембран и электрохимического осаждения, а также проводится детальное изучение их морфологических и магнитных свойств.

\section{2. Методика}

Темплатами для синтеза железных нанотрубок служили трековые мембраны на основе полиэтилентерефталата (ПЭТФ). В качестве основы для создания темплатов применялась пленка ПЭТФ толщиной $12 \mu \mathrm{m}$, которая облучалась быстрыми тяжелыми ионами ${ }^{132} \mathrm{Xe}^{22+}$ с энергией $1.75 \mathrm{MeV} /$ nucleon и флюенсом $1 \cdot 10^{9} \mathrm{~cm}^{-2}$ на ускорителе ДЦ-60 (Астана, Казахстан). Сенсибилизация облученных пленок осуществлялась при помощи УФ-лампы (длина волны $253.7 \mathrm{~nm}$ ) с каждой стороны в течение $30 \mathrm{~min}$. Образовавшиеся в результате облучения высокодефектные области (латентные треки) трансформировались в поры посредством химического 

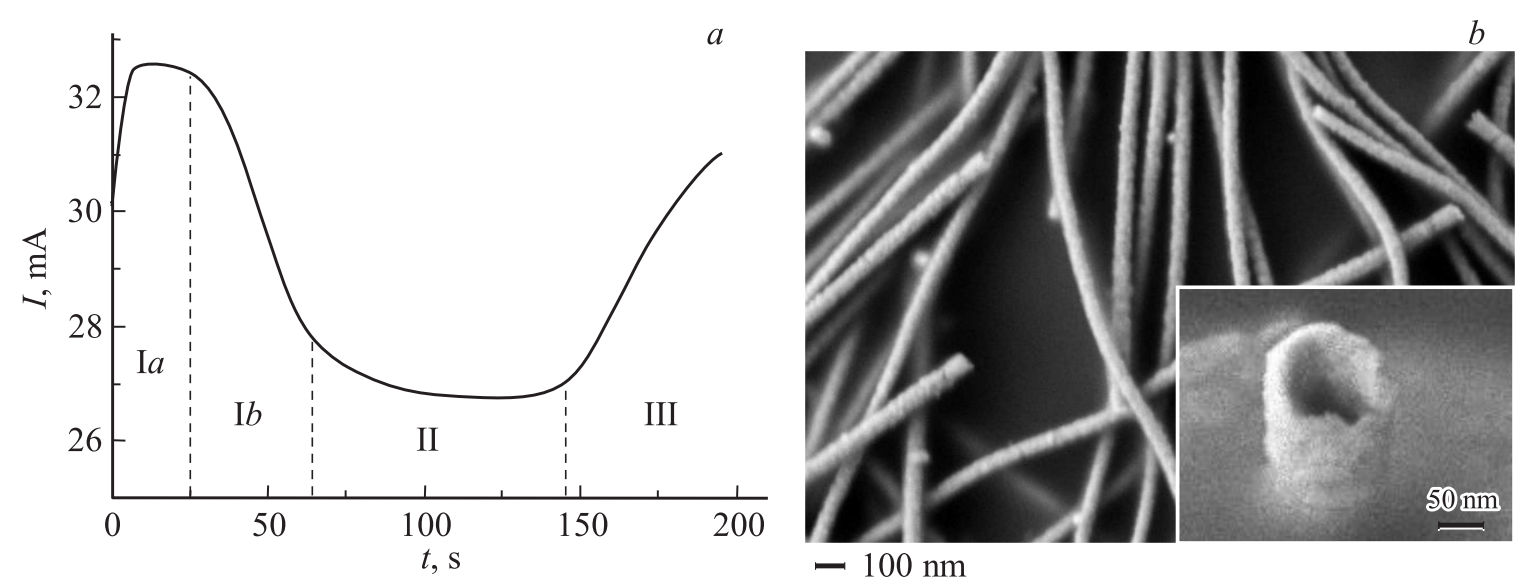

Рис. 1. Хроноамперограмма процесса электрохимического осаждения железных нанотрубок в поры ПЭТФ-темплата $(a)$ и РЭМ-изображение массива нанотрубок после удаления темплата $(b)$. На вставке - сколотая у основания нанотрубка.

травления в растворе $2.2 \mathrm{M} \mathrm{NaOH}$ при температуре $85 \pm 1^{\circ} \mathrm{C}$ в течение $4.5 \mathrm{~min}$, после чего полученные темплаты обрабатывались в нейтрализующем растворе (водный $1 \%$ раствор уксусной кислоты) и промывались в деионизированной воде. Поры имели цилиндрическую форму со средним диаметром $110 \pm 3 \mathrm{~nm}$.

Заполнение пор металлом осуществлялось методом электрохимического осаждения. Для этого из полученных трековых мембран вырезались отдельные куски прямоугольной формы размером $10 \times 15 \mathrm{~mm}$. На них методом магнетронного напыления в вакууме наносился слой золота толщиной $10 \mathrm{~nm}$, который служил рабочим электродом (катодом) при осаждении. Темплаты с напыленными золотыми пленками плотно прижимались к держателю таким образом, чтобы обеспечить возможность доступа электролита к катоду исключительно через поры. Осаждение проводилось в потенциостатическом режиме при напряжении $U=1.25 \mathrm{~V}$ в электролите следующего состава: $\mathrm{FeSO}_{4} \cdot 7 \mathrm{H}_{2} \mathrm{O}$ (234.5 g/l), $\mathrm{FeCl}_{2} \cdot 6 \mathrm{H}_{2} \mathrm{O}(1.16 \mathrm{~g} / \mathrm{l}), \mathrm{H}_{3} \mathrm{BO}_{3}(45 \mathrm{~g} / \mathrm{l}), \mathrm{C}_{6} \mathrm{H}_{8} \mathrm{O}_{6}(1 \mathrm{~g} / \mathrm{l})$. Степень заполнения пор металлом контролировали хроноамперометрическим методом, регистрируя силу тока мультиметром Agilent 34410A.

Состав, морфологические и структурные особенности электроосажденных железных наноструктур изучались на растровом электронном микроскопе (РЭМ) Hitachi TM3030, оснащенном системой энергодисперсионного анализа (ЭДА) Bruker XFlash MIN SVE при ускоряющем напряжении $15 \mathrm{kV}$. Внутренние диаметры железных нанотрубок измерялись манометрическим методом определения газопроницаемости [20] с использованием прибоpa Sartocheck (R) 3 Plus 16290. Диапазон измеряемых давлений лежал в пределах от 8 до $20 \mathrm{kPa}$. Прецизионный контроль внешних и внутренних диаметров нанотрубок проводился с помощью просвечивающей электронной микроскопии (ПЭМ) на установке JEM-100 при ускоряющем напряжении $100 \mathrm{kV}$. Кристаллическая структура металлической фазы исследовалась при дифракции электронов в выбранной области на просвечивающем электронном микроскопе JEM-100, также был проведен рентгеноструктурный анализ (РСА) на дифрактометре D8 ADVANCE с использованием $\mathrm{Cu} K_{\alpha}$-излучения и графитового монохроматора. Дифрактограммы записывались в диапазоне углов $2 \theta=10-90^{\circ}$ с шагом $0.02^{\circ}$ в течение $5 \mathrm{~s}$ в каждой точке.

Величины основных магнитных параметров определялись с помощью данных вибрационного магнитометра универсальной измерительной системы „Liquid Helium Free High Field Measurement System (Cryogenic LTD)“. Измерения выполнялись индукционным методом, при этом наведенная электродвижущая сила индукции в сигнальных катушках изменялась колеблющимся с определенной частотой намагниченным образцом в интервале магнитных полей $B \pm 3$ Т при температурах в диапазоне $T=100-300 \mathrm{~K}$.

Тонкие магнитные параметры определялись на мессбауэровском спектрометре MS1104Em, работающем в режиме постоянных ускорений с треугольной формой изменения доплеровской скорости движения источника относительно поглотителя. В качестве источника выступали ядра ${ }^{57}$ Со в матрице Rh. Калибровка мессбауэровского спектрометра осуществлялась при комнатной температуре с помощью стандартного поглотителя $\alpha$-Fe. Для обработки и анализа результатов использовались методы анализа распределений сверхтонких параметров мессбауэровского спектра и модельной расшифровки спектра с учетом априорной информации об объекте исследования, реализованные в программе SpectrRelax.

\section{3. Результаты и обсуждение}

Известно, что электроосаждение железа в поры темплатов обычно происходит в четыре стадии [21-23], которые хорошо видны на временной зависимости процесса (рис. $1, a)$. Первой стадии $(\mathrm{I} a)$ соответствует процесс образования зародышей на катодном слое золота и на внутренней поверхности пор. Поскольку на этом 

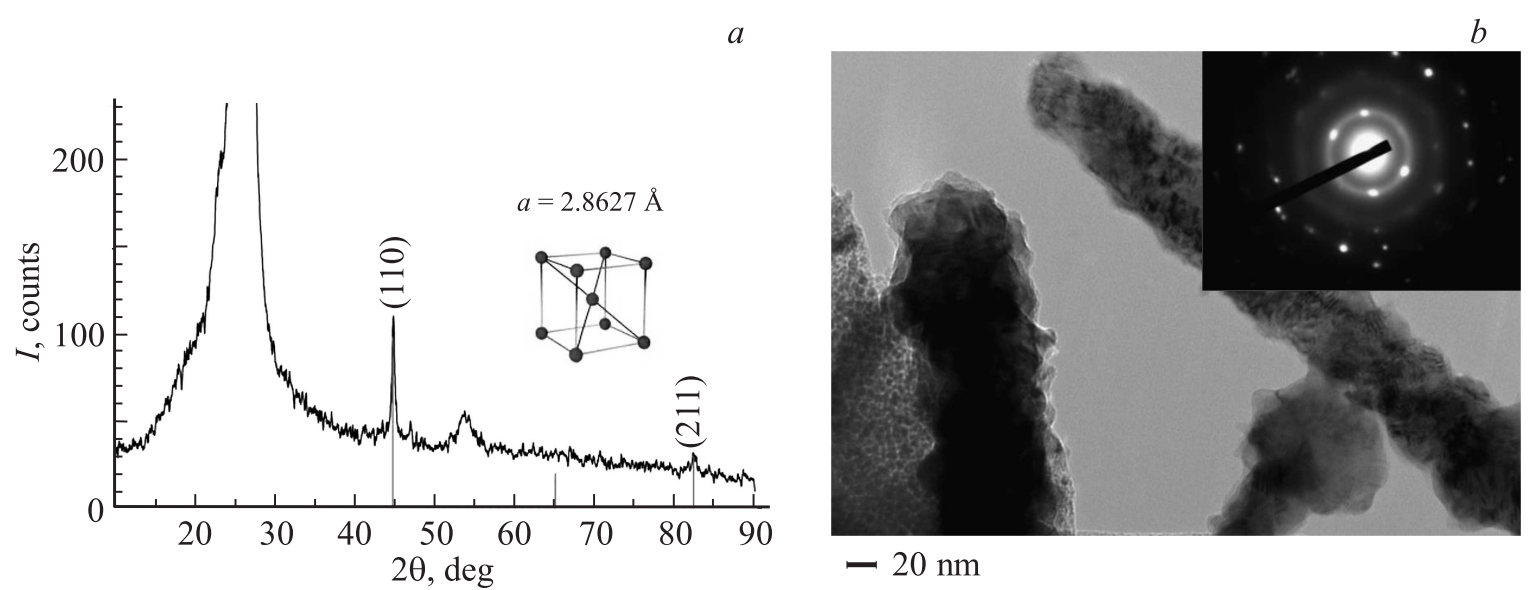

Рис. 2. Рентгеновская дифрактограмма железных нанотрубок $(a)$ и ПЭМ-изображение $(b)$. На вставке - картина дифракции электронов в выбранной области.

этапе процесс восстановления металла носит трехмерный характер, величина тока $I$ имеет большие значения (более $32 \mathrm{~mA})$. Стадия І $а$ завершается примерно через $t=20 \mathrm{~s}$, когда образуется основание нанотрубки, представляющее собой кольцо железного осадка на катодном слое $(\mathrm{I} b)$. Значение силы тока снижается примерно до $27 \mathrm{~mA}$ вследствие уменьшения концентрации ионов железа в объеме пор и перехода к двумерному (послойному) росту нанотрубки. Вторая стадия (II), начинающаяся при $t=60 \mathrm{~s}$, является основной фазой процесса, в течение которой происходит увеличение длины нанотрубок. Направление роста наноструктур соответствует приоритетным кристаллографическим направлениям и зависит от условий процесса осаждения. Сила тока в течение этой стадии процесса осаждения железа практически не снижается $(I=27 \mathrm{~mA})$ вследствие того, что концентрация ионов внутри поры меняется незначительно. Начало третьей стадии (III, $t=150 \mathrm{~s})-$ осаждение металла на поверхности темплата с образованием „крышечек“ над трубками - характеризуется возрастанием силы тока из-за более высокой концентрации ионов железа над поверхностью темплата, чем в порах, и трехмерным ростом металлического осадка. На четвертой стадии (на зависимости процесса $I(t)$ не указана) разрастающиеся „крышечки“ образуют сплошной слой на поверхности темплата, и дальнейшее осаждение приводит лишь к увеличению толщины слоя металла. Следует отметить, что поведение $I(t)$ на хроноамперограммах зависит от параметров осаждения [22,24] и формы пор [25]. Рост нанотрубок для исследования их структурных и магнитных характеристик был ограничен третьей стадией осаждения, при этом время осаждения составляло $t=140 \mathrm{~s}$.

РЭМ-изображение полученных нанотрубок после удаления (вытравливания) полимерной матрицы приведено на рис. $1, b$. Видно, что длина нанотрубок соответствует начальной толщине темплата $(12 \mu \mathrm{m})$, а их внешний диаметр - среднему диаметру пор $(110 \mathrm{~nm})$, при этом аспектное соотношение составит порядка 100.
РЭМ-изображение скола трубки (вставка к рис. 1, $b$ ) дает возможность утверждать, что полученные наноструктуры имеют полую форму, однако такое исследование не позволяет определить внутренний диаметр и толщину стенок трубок. Для нахождения этих параметров был использован метод газопроницаемости [26], с использованием которого было установлено, что средние значения внутренних диаметров нанотрубок составляют $69 \pm 1 \mathrm{~nm}$, а толщина стенок $-20 \mathrm{~nm}$.

Химический состав нанотрубок, определенный на основании ЭДА-спектров, показал, что нанотрубки на $100 \%$ состоят из железа без каких-либо оксидных или солевых примесей. Анализ фазового состава нанотрубок методом РСА (рис. 2,a) позволил установить, что исследуемые образцы однофазны, обладают объемно центрированной кубической (ОЦК) структурой $\alpha$-железа (пространственная группа $\operatorname{Im} 3 m$ ) с выделенными плоскостями роста (110) и (211). Гало при $2 \theta=15-35^{\circ}$ и средний максимум $2 \theta=54^{\circ}$ соответствуют материалу темплата (ПЭТФ) [27]. При этом на дифрактограмме исследуемого образца наблюдаются уширенные пики, характерные для дифракции на наноразмерных объектах. Средний размер кристаллитов $\tau$, рассчитанный по уравнению Шерера, составил $21.9 \mathrm{~nm}$. Параметр кристаллической решетки $(a=2.8627 \AA)$ отличается от эталонного значения $(a=2.866 \AA)$.

Анализ ПЭМ-изображений (рис. 2,b) подтверждает, что величины внешних диаметров железных нанотрубок составляют $110 \mathrm{~nm}$ вдоль всей длины с незначительными отклонениями. Поверхность наноструктур шероховатая, что является следствием использования пористых пленок ПТЭФ как шаблонов для роста наноструктур [28]. Изучение картин дифракции электронов в выбранной области (вставка к рис. 2,b) подтверждает, что нанотрубки имеют ОЦК-структуру. Уширение гало на дифракционной картине указывает на то, что стенки имеют мелкодисперсный характер. Расчет размеров отдельных кристаллитов железа из радиального уширения дифракционного кольца показал, что они составляют 

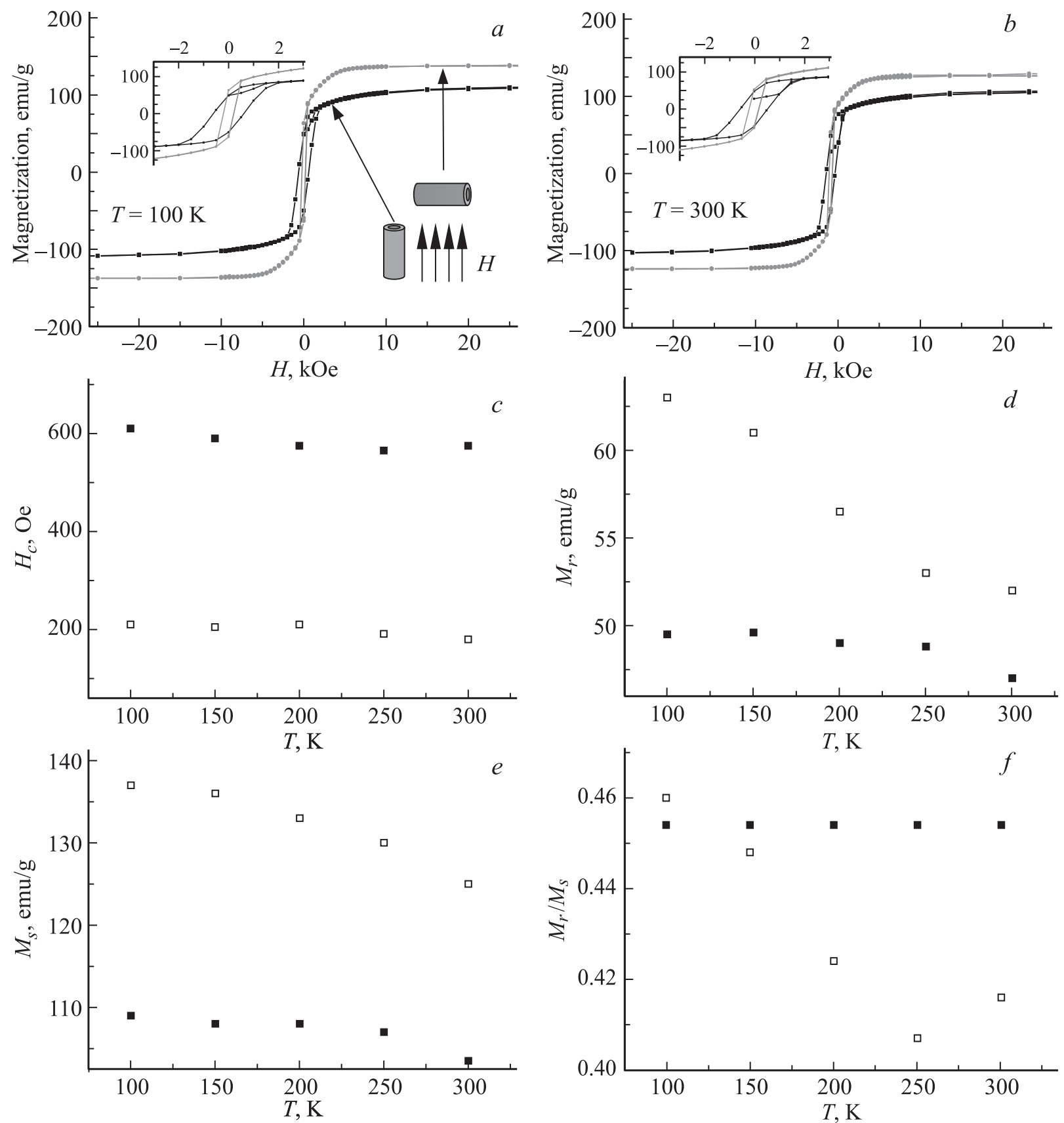

Рис. 3. Магнитные характеристики железных нанотрубок при параллельном и перпендикулярном направлении магнитного поля относительно ориентации нанотрубок. Зависимость намагниченности от магнитного поля при $100(a)$ и $300 \mathrm{~K}(b)$. На вставках представлены увеличенные фрагменты петель. Зависимости коэрцитивности $(c)$, остаточной намагниченности $(d)$, намагниченности насыщения $(e)$ и коэффициента прямоугольности петель гистерезиса $(f)$ от температуры. Темные квадраты на частях $c-f$ соответствуют параллельной ориентации поля относительно оси нанотрубок, светлые - перпендикулярной.

порядка $20 \mathrm{~nm}$, что хорошо согласуется с данными РСА. Поликристаллическая структура нанотрубок со средним размером отдельного кристаллита, соответствующим толщине стенки, вместе с параметром кристаллической решетки, отличающимся от эталонного значения, свидетельствуют о их деформации из-за дефектов, образующихся в процессе роста трубок.
Определение зависимости намагниченности от магнитного поля $M(H)$ для его параллельной и перпендикулярной ориентации относительно оси нанотрубок проводилось при температурах в интервале $100-300 \mathrm{~K}$. Значение индукции магнитного поля изменялось в пределах $\pm 3 \mathrm{~T}$. Характерный вид зависимостей $M(H)$ приведен на рис. $3, a$ и $b$. 


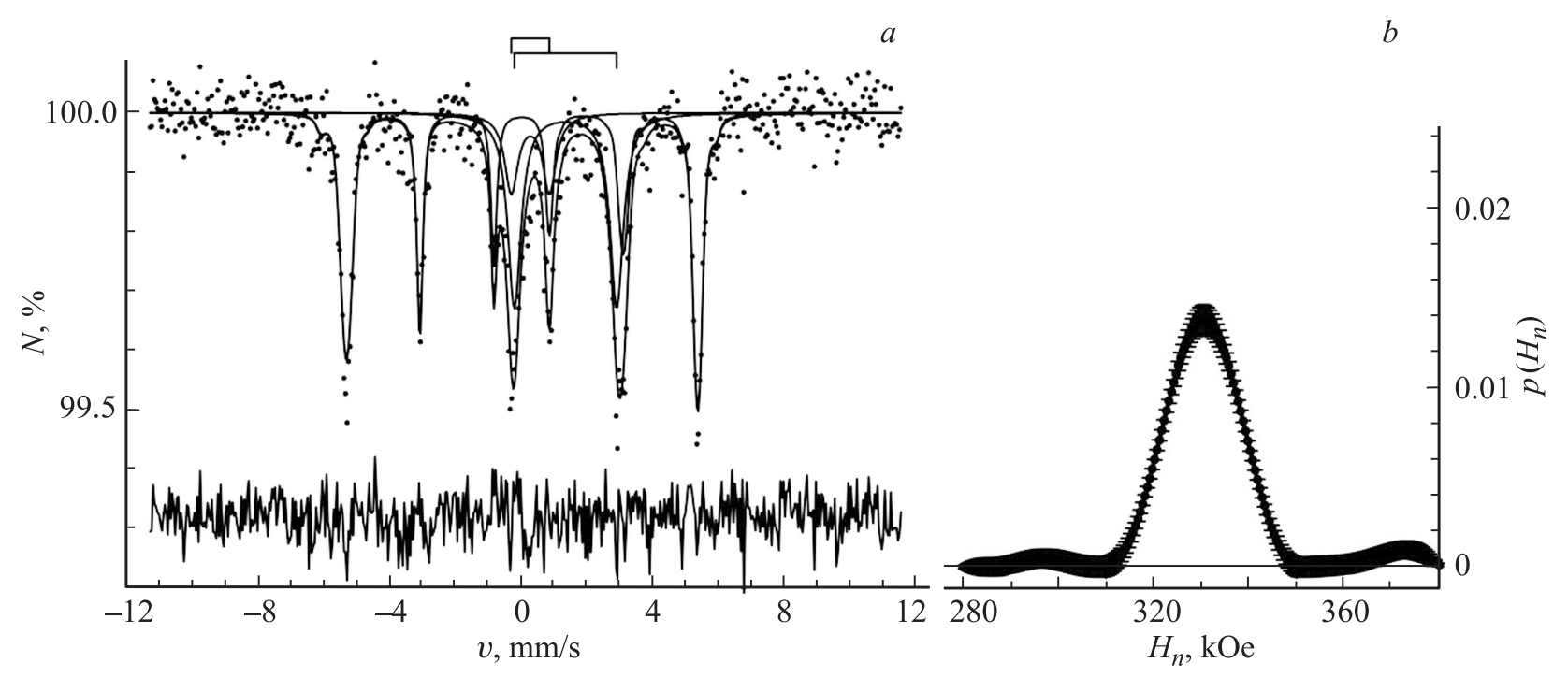

Рис. 4. Результаты обработки мессбауэровского спектра ядер ${ }^{57} \mathrm{Fe}(a)$ и восстановленное при этом распределение сверхтонкого магнитного поля $H_{n}(b)$. Нижняя линия на части $a$ отражает расхождение экспериментальных данных по измерению мессбауэровского спектра с результатами обработки.

Исследования поведения намагниченности массивов железных нанотрубок в магнитном поле показали, что вид петель гистерезиса соответствует группе магнитожестких материалов, однако значение коэрцитивности при этом меньше, чем для массивных железных тел. Также следует отметить, что магнитные свойства железных нанотрубок схожи со свойствами аналогичных нанопроволок [29-31]. На основании петель гистерезиса были определены основные магнитные характеристики нанотрубок $\left(H_{c}-\right.$ коэрцитивность, $M_{r}-$ остаточная намагниченность, $M_{s}$ - намагниченность насыщения, $M_{r} / M_{s}$ - коэффициент прямоугольности петли гистерезиса) и их температурные зависимости (рис. $3, c-f)$.

Коэрцитивность нанотрубок (рис. 3,c) во всем температурном диапазоне имеет практически постоянные значения. Слабая зависимость $H_{c}(T)$ связана с тем, что исследуемый интервал находится далеко от температуры Кюри железа $(1043 \mathrm{~K})$. Отметим, что в исследуемых образцах наблюдается магнитная анизотропия: во всем температурном интервале значения $H_{c}$ при параллельной ориентации поля относительно оси нанотрубок в 3 раза превышают значения для перпендикулярного направления поля. Поскольку при проведении структурных исследований кристаллической анизотропии выявлено не было, фактором, определяющим появление магнитной анизотропии, будет анизотропия формы [32,33]. Ее влияние объясняется тем, что при введении внешнего магнитного поля у нанотрубок с высоким аспектным соотношением $(\sim 100)$ энергия размагничивания вдоль их оси имеет бо́льшие значения, чем при перпендикулярном направлении поля.

Из кривых остаточной намагниченности (рис. 3, $d$ ) и намагниченности насыщения нанотрубок (рис. 3,e) видно, что эти величины для различной ориентации трубок относительно магнитного поля во всем исследуе- мом интервале температур сильно различаются, причем с повышением температур это различие уменьшается. Такое различие, так же как и в случае коэрцитивности, является следствием анизотропии формы, а его уменьшение связано с разрушением магнитного порядка за счет увеличения влияния тепловых колебаний при нагреве образца. Из рис. $3, f$ видно различие в коэффициенте прямоугольности при разных температурах. Такая зависимость может быть связана либо с обменным, либо с магнитостатическим дипольным взаимодействием. С учетом того, что ПЭТФ-темплат неспособен служить связующим звеном в таких процессах уже на дистанции более нескольких межатомных расстояний, взаимное влияние между нанотрубками осуществляется только через магнитостатические дипольные взаимодействия.

Тонкие магнитные параметры железных нанотрубок определялись методом мессбауэровской спектроскопии, результаты которой приведены на рис. 4.

Мессбауэровский спектр для железных нанотрубок (рис. 4,a), полученный при комнатной температуре, представляет собой зеемановский секстет и два квадрупольных дублета. Спектр обработан методом восстановления распределения сверхтонкого магнитного поля (рис. $4, b)$ и методом модельной расшифровки. Видно, что максимум восстановленного распределения сверхтонкого магнитного поля достигается при $H_{n} \cong 330 \mathrm{kOe}$. Средние значения сдвига $\delta$ мессбауэровской линии и квадрупольного смещения $\varepsilon$ для зеемановского секстета близки к нулю. Следовательно, зеемановский секстет соответствует $\alpha$-Fe. Значения сдвигов квадрупольных дублетов, лежащие в диапазонах $1.27-1.35$ и $0.20-0.42 \mathrm{~mm} / \mathrm{s}$, позволяют идентифицировать их как парциальные спектры катионов $\mathrm{Fe}^{2+}$ и $\mathrm{Fe}^{3+}$, находящихся в парамагнитном состоянии. С учетом полученных данных определено влияние вкладов парциальных спек- 
тров катионов $\mathrm{Fe}^{2+}$ и $\mathrm{Fe}^{3+}$, которое для $\mathrm{Fe}^{2+}$ составило $24 \%$, для $\mathrm{Fe}^{3+}-15 \%$. Поскольку при проведении исследований методами ЭДА, РСА и дифракции электронов оксидов и солей железа в нанотрубках выявлено не было, детектирование катионов $\mathrm{Fe}^{2+}$ и $\mathrm{Fe}^{3+}$ происходит за счет специфического распределения общего электронного облака в кристаллической решетке.

В результате модельной расшифровки мессбауэровских спектров железных нанотрубок были получены значения квадрупольного смещения $\varepsilon=0.002 \pm 0.004 \mathrm{~mm} / \mathrm{s}$, a также сдвига мессбауэровской линии $\delta=$ $=0.002 \pm 0.004 \mathrm{~mm} / \mathrm{s}$. Средние значения квадрупольного смещения $\varepsilon$ и изомерного сдвига $\delta$ примерно равны нулю, при этом среднее значение сверхтонкого магнитного поля $H_{n}=330 \pm 0.6 \mathrm{kOe}$. Приведенные значения сверхтонких параметров соответствуют значениям для ядер ${ }^{57} \mathrm{Fe}$ в эталонных массивных образцах $\alpha$-Fе. Отношения интенсивностей второй и пятой к интенсивностям первой и шестой резонансных линий наблюдаемого зеемановского секстета (рис. 4,a) зависят от угла между направлением пролета гамма-кванта и магнитным полем в образце и указывают на отсутствие в них магнитной текстуры. При этом наблюдается случайное распределение направлений магнитных моментов атомов железа. Принимая во внимание слабую температурную зависимость $H_{c}$ и $M_{s}$ (рис. 3), можно сделать вывод, что в образце отсутствует магнитокристаллическая анизотропия.

\section{4. Заключение}

С использованием ионно-трековой технологии получены ПЭТФ-шаблоны толщиной $12 \mu \mathrm{m}$, содержащие цилиндрические поры диаметром $110 \mathrm{~nm}$. Электрохимическим методом синтезированы железные наноструктуры, имеющие форму полых нанотрубок с внешними геометрическими размерами, соответствующими параметрам пор ПЭТФ-темплата, и внутренним диаметром $70 \mathrm{~nm}$. Стенки нанотрубок имеют поликристаллическую структуру, при этом размер отдельного кристаллита составляет порядка $20 \mathrm{~nm}$, что соответствует толщине стенки. Этот факт свидетельствует о том, что стенка формируется из отдельных кристаллитов, растущих друг над другом. Анализ состава нанотрубок показал, что они на $100 \%$ состоят из железа без оксидных или солевых примесей. Наноструктуры однофазны и обладают ОЦК-структурой $\alpha$-Fe c параметром кристаллической решетки $a=2.8627 \AA$.

Анализ магнитных свойств образцов позволил сделать вывод, что характеристики нанотрубок сопоставимы с магнитными свойствами железных нанопроволок. Показано наличие анизотропии магнитных свойств, которая связана с анизотропией формы обладающих большим аспектным соотношением ( 100) нанотрубок. Установлено незначительное уменьшение основных магнитных параметров исследуемых образцов при нагреве за счет увеличения вклада тепловых колебаний, разрушающих магнитный порядок. Определено, что нанотрубки не имеют магнитной текстуры из-за случайного распределения направлений магнитных моментов атомов железа.

\section{Список литературы}

[1] D.T. Mitchell, S.B. Lee, L. Trofin, N. Li, T.K. Nevanen, H. Söderlund, C.R. Martin. J. Am. Chem. Soc. 124, 11864 (2002).

[2] S.K. Yen, P. Padmanabhan, S.T. Selvan. Theranostics 3, 986 (2013).

[3] B. Kalska-Szostko, E. Orzechowska, U. Wykowska. Colloids Surf. B 111, 509 (2013).

[4] M. Safi, M. Yan, M.A. Guedeau-Boudeville, H. Conjeaud, V. Garnier-Thibaud, N. Boggetto, A. Baeza-Squiban, F. Niedergang, D. Averbeck, J.F. Berret. ACS Nano. 5, 5354 (2011).

[5] S.R. Dave, X. Gao. Wiley Interdiscip. Rev.: Nanomed. Nanobiotechnol. 1, 583 (2009).

[6] C.R. Martin. Science 266, 1961 (1994).

[7] L. Dauginet-De Pra, E. Ferain, R. Legras, S. DemoustierChampagne. Nucl. Instrum. Meth. Phys. Res. B 196, 81 (2002).

[8] E.Y. Kaniukov, J. Ustarroz, D.V. Yakimchuk, M. Petrova, H. Terryn, V. Sivakov, A.V. Petrov. Nanotechnology 27, 115305 (2016)

[9] L.G. Vivas, Y.P. Ivanov, D.G. Trabada, M.P. Proenca, O. Chubykalo-Fesenko. Nanotechnology 24, 105703 (2013).

[10] Y.A. Ivanova, D.K. Ivanov, A.K. Fedotov, E.A. Streltsov, S.E. Demyanov, A.V. Petrov, E.Y. Kaniukov, D. Fink. J. Mater. Sci. 42, 9163 (2007).

[11] V. Haehnel, S. Fähler, P. Schaaf, M. Miglierini, C. Mickel, L. Schultz, H. Schlörb. Acta Mater. 58, 2330 (2010).

[12] L. Boarino, S. Borini, G. Amato. J. Electrochem. Soc. 156, K223 (2009).

[13] J. Qin, J. Nogués, M. Mikhaylova, A. Roig, J.S. Muñoz, M. Muhammed. Chem. Mater. 17, 1829 (2005).

[14] S.E. Demyanov, E.Y. Kaniukov, A.V. Petrov, E.K. Belonogov, E.A. Streltsov, D.K. Ivanov, Y.A. Ivanova, C. Trautmann, H. Terryn, M. Petrova, J. Ustarroz, V. Sivakov. J. Surf. Invest. $X$-ray, Synchrotron Neutron Tech. 8, 805 (2014).

[15] Z. Hua, S. Yang, H. Huang, L. Lv, M. Lu, B. Gu, Y. Du. Nanotechnology 17, 5106 (2006).

[16] D. Zhou, T. Wang, M.G. Zhu, Z.H. Guo, W. Li, F.S. Li. J. Magnetics 16, 413 (2011).

[17] X.F. Han, Z.C. Wen, H.X. Wei. IEEE Trans. Magn. 47, 2957 (2011).

[18] H. Hillebrenner, F. Buyukserin, J.D. Stewart, C.R. Martin. Nanomedicine (London) 1, 39 (2006).

[19] S.-H. Liao, K.-L. Chen, C.-M. Wang, J.-J. Chieh, H.-E. Horng, L.-M. Wang, C. Wu, H.-C. Yang. Sensors 14, 21409 (2014).

[20] B. Tylkowski, I. Tsibranska. J. Chem. Technol. Met. 50, 3 (2015).

[21] B. Yoo, F. Xiao, K.N. Bozhilov, J. Herman, M. Ryan, N.V. Myung. Adv. Mater. 19, 296 (2007).

[22] M. Motoyama, Y. Fukunaka, T. Sakka, Y.H. Ogata. Electrochim. Acta 53, 205 (2007).

[23] T.N. Narayanan, M.M. Shaijumon, L. Ci, P.M. Ajayan, M.R. Anantharaman. Nano Res. 1, 465 (2008). 
[24] C. Schönenberger, B.M.I. van der Zande, L.G.J. Fokkink, M. Henny, C. Schmid, M. Krüger, A. Bachtold, R. Huber, H. Birk, U. Staufer. J. Phys. Chem. 101, 5497 (1997).

[25] M. Motoyama, Y. Fukunaka, T. Sakka, Y.H. Ogata, S. Kikuchi. J. Electroanal. Chem. 584, 84 (2005).

[26] E. Kaniukov, A. Kozlovsky, D. Shlimas, D. Yakimchuk, M. Zdorovets, K. Kadyrzhanov. IOP Conf. Ser.: Mater. Sci. Eng. 110, 012013 (2016).

[27] C. Guillén, J. Herrero. Thin Solid Films 480, 129 (2005).

[28] M.E. Toimil-Molares. Beilstein J. Nanotechnol. 3, 860 (2012).

[29] M. Krajewski, W.S. Lin, H.M. Lin, K. Brzozka, S. Lewinska, N. Nedelko, A. Slawska-Waniewska, J. Borysiuk, D. Wasik. Beilstein J. Nanotechnol. 6, 1652 (2015).

[30] S. Yang, H. Zhu, D. Yu, Z. Jin, S. Tang, Y. Du. J. Magn. Magn. Mater. 222, 97 (2000).

[31] H. Zeng, R. Skomski, L. Menon, Y. Liu, S. Bandyopadhyay, D.J. Sellmyer. Phys. Rev. B 65, 134426 (2002).

[32] M. Almasi Kashi, A. Ramazani, A.S. Esmaeily. IEEE Trans. Magn. 49, 1167 (2013).

[33] D.J. Sellmyer, M. Zheng, R. Skomski. J. Phys.: Condens. Matter 13, R433 (2001). 